\title{
Poly(3-methylthiophene) modified gold sensor for determination of 3,4-dihydroxyphenylacetic acid, ascorbic acid and uric acid in biological fluids using voltammetric techniques
}

\author{
Ebru KUYUMCU SAVAN 1 *, Gamze ERDOĞDU ${ }^{2}$ \\ 1 Department of Basic Pharmaceutical Sciences, Faculty of Pharmacy, İnönü University, Malatya, Turkey. \\ 2 Department of Chemistry, Faculty of Science, İnönü University, Malatya, Turkey. \\ * Corresponding Author. E-mail: ebru.savan@inonu.edu.tr (E.K.S.); Tel. +90-(422) 341-1216; ORCID No: 0000-0002- \\ 8851-0907.
}

Received: 01 June 2018 / Revised: 31 August 2018 / Accepted: 03 September 2018

\begin{abstract}
Electrochemical polymerization was carried out in a one-compartment cell containing deaerated acetonitrile, and $100 \mathrm{mM}$ tetrabutylammonium tetrafluoroborate monomer of 3-methylthiophene. The polymer films were grown on a gold electrode by bulk electrolysis at $1.700 \mathrm{~V}\left(\mathrm{vs} . \mathrm{Ag} / \mathrm{Ag}^{+}\right)$. The modified sensor showed an excellent electrocatalytic effect towards oxidation of the mixture of 3,4-dihydroxyphenylacetic acid (DOPAC), ascorbic acid and uric acid, which appeared at a $\mathrm{pH}$ range of 2-11 by differential pulse voltammetry (DPV) techniques. The best results for determination of DOPAC were obtained by DPV in PBS ( $\mathrm{pH} 7.00)$. A calibration curve was obtained in the DOPAC concentration range of $1.0-50.0 \mu \mathrm{M}(\mathrm{r}=0.9948)$. Limit of detection and limit of quantification were found as $0.066 \mu \mathrm{M}$ and $0.220 \mu \mathrm{M}$, respectively. The results of the experiments indicated that the sensor has good stability, sensitivity and reproducibility for at least one month if stored in dry air.
\end{abstract}

KEYWORDS: Poly (3-methylthiophene); 3,4-dihydroxyphenylacetic acid; ascorbic acid; uric acid; voltammetry.

\section{INTRODUCTION}

3,4-Dihydroxyphenylacetic acid (DOPAC) is an important metabolite of dopamine (DA), which is an important neurotransmitter involved in motor and cognitive functions, and deficits of DA may cause Parkinson's disease (PD) [1-3]. It is important to monitor DA and DOPAC, because the amount of DA is key in the treatment of PD and Alzheimer's diseases, as well as major depressive disorder [4]. The chemical process of DA may be assessed in the frontal lobe of the brain by measuring the extracellular amounts of DOPAC [2,5]. Usually, DOPAC coexists at very low concentration (micro molar range) with ascorbic acid (AA) and uric acid (UA) in biological fluids [6-8]. Thus, simultaneous determination of DOPAC, AA and UA with selectivity and sensitivity is crucial in the fields of medicine and chemistry, and it has considerable effects for diagnostic and pathological research $[2,9]$.

Several techniques including voltammetry [5,10-17], high-performance liquid chromatography [18], chemiluminescence [19] and fluorometry $[2,20]$ have been used for determination of DOPAC. It is desirable to develop a simple and fast alternative method for determination of neurotransmitters in the presence of interferences. Electroanalytical methods may be attractive in measuring neurotransmitters and their metabolites through their electrochemical activities. However, anodic potentials of AA, DOPAC and UA (Figure 1) are almost overlapped at unmodified electrodes, and also they are resulted in very low selectivity and sensitivity due to the deposition of the oxidized products and contamination effects on the electrode surface $[1,10]$. The electrodes can be modified with conductive polymers for stable and selective determination of DOPAC [21-25].

Poly (3-methylthiophene) (3MT) is a highly conductive polymer which belongs to the class of nondegenerated ground symmetrical conjugated polymers. Poly (3MT) has electrochromic properties such as response time of several milliseconds and recyclability above 105 cycles [26]. Poly (3MT) shows characteristic and reversible changes of conductivity and other properties under oxidation and reduction (switching) [27].

How to cite this article: Kuyumcu Savan E and Erdoğdu G. Poly(3-methylthiophene) modified gold sensor for determination of 3,4dihydroxyphenylacetic acid, ascorbic acid and uric acid in biological fluids using voltammetric techniques. J Res Pharm. $2019 ; 23$ (1): $25-33$. 
High quality freestanding films of poly (3MT) can easily be obtained by oxidation of the 3MT monomer in a tetrabutylammonium tetrafluoroborate (TBATFB) electrolyte solution [28-30]. Poly (3MT) exhibits excellent electrocatalytic effects on some compounds with conjugated double bonds in their molecular structure [30].

In this study, we wish to present the highly conductive poly (3MT) which was fabricated by an electrochemical deposition process on gold electrode surface in a non-aqueous medium to achieve simultaneous determination of neurotransmitters and interferences. The poly (3MT) film showed significant results for determination of AA, DOPAC and UA. To examine the analytical method's usability, neurotransmitters and interferences were spiked in blood serum, urine samples and tablets, and the results were found to be satisfactory.<smiles>CC(C)(O)O</smiles><smiles>O=c1[nH]c(=O)c2[nH]c(=O)[nH]c2[nH]1</smiles><smiles>O=C1OC(C(O)CO)C(O)=C1O</smiles>

Figure 1. Chemical structures of DOPAC, AA and UA [1].

\section{RESULTS AND DISCUSSION}

\subsection{Electrochemical polymerization of 3-Methylthiophene}

The polymer films were grown on gold electrode surface by bulk electrolysis at a constant potential of $1.7 \mathrm{~V}$ (vs. Ag/ $\mathrm{Ag}^{+}$). Polymer film-thickness is important in electrochemical polymerization, and the poly (3MT) films were grown at 10,15, 20, 25, 30 seconds at constant potential using bulk electrolysis technique. The highest electrocatalytic activity against AA, DOPAC and UA was obtained by the poly (3MT) film deposited for $10 \mathrm{~s}$, and the maximum peak current was $0.412 \mu \mathrm{A}$ at $0.200 \mathrm{~V}$ for $0.1 \mathrm{mM}$ DOPAC. DOPAC was also oxidized at $0.340 \mathrm{~V}$ at bare gold electrode. The modified sensor shifted the oxidation potential for DOPAC to a more negative potential. This suggests that the film has electrocatalytic characteristics, and while film thickness increases, it prevents transition of DOPAC which has large molecular size, so it makes one think that the film exhibits perm-selective behaviour. Additionally, the polymer formed in these conditions had the best electrochemical behaviour, the sharpest voltammetric peak responses and the most stable poly (3MT) films. It was also observed that the thicker polymer films had less homogeneity (surface gaps and cracks) and less strength than films grown at $10 \mathrm{~s}$. The polymerization conditions were selected according to detailed experiments. In order to obtain the optimum experimental conditions, effects of the variables on the peak current and the peak potential ( $\mathrm{pH}$ and species of supporting electrolyte) were investigated for DOPAC at the poly (3MT) / Au electrode by DPV.

\subsection{Effect of supporting electrolyte and $\mathrm{pH}$}

In order to determine the effects of $\mathrm{pH}$ and the supporting electrolyte, a phosphate buffer solution (PBS), $\mathrm{Na}_{2} \mathrm{SO}_{4}, \mathrm{KCl}, \mathrm{NaNO}_{3}, \mathrm{NaCl}$ and $\mathrm{NaClO}_{4}$ electrolytes were used. DPV measurements of $0.1 \mathrm{mM}$ DOPAC were made in each electrolyte to decide the electrolyte to work on, and the highest and best response $(0.412 \mu \mathrm{A}$ at $0.2 \mathrm{~V}$ ) were obtained in PBS (Figure 2). Phosphate buffer solution was selected as the supporting electrolyte, and $\mathrm{pH}$ effect on peak current and potential was investigated. The examination was made in $0.1 \mathrm{M}$ PBS at a $\mathrm{pH}$ range of 3 to 11 including $0.1 \mathrm{mM}$ DOPAC using DPV techniques. The peak potential was strongly $\mathrm{pH}-$ dependent. As it can be seen in Figure 3, the peak potential of the anodic progress showed decreasing negative potential values with increasing $\mathrm{pH}$. Furthermore, the best peak shape and current of DOPAC were obtained at $\mathrm{pH}$ 7.0. Consequently, DPV techniques and 0.1 M PBS ( $\mathrm{pH} 7.0)$ were chosen for the following electroanalytical studies. 


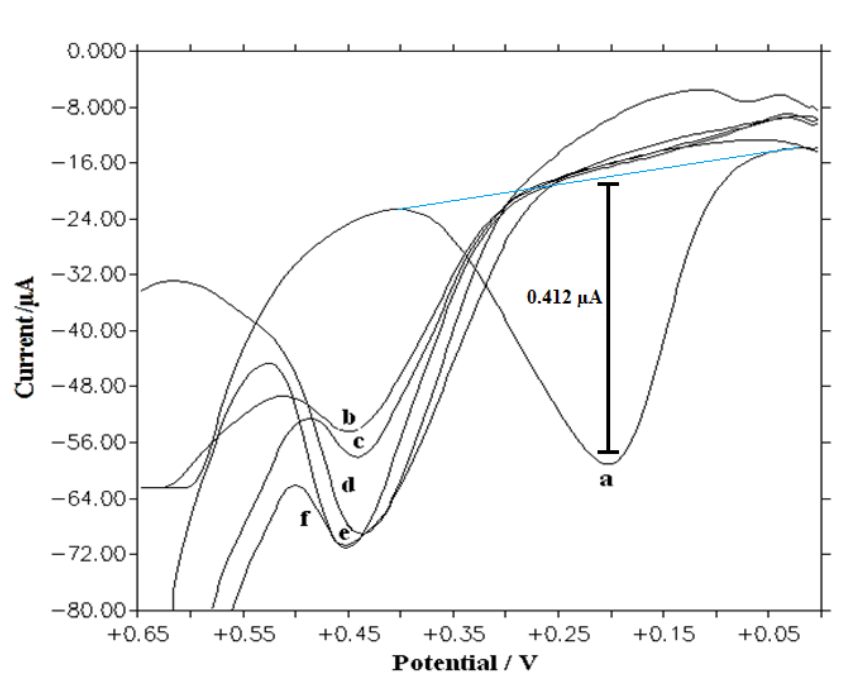

Figure 2. DPVs of $0.1 \mathrm{mM}$ DOPAC in $0.1 \mathrm{M}$ a) PBS (pH 7.0) b) $\mathrm{KCl}$ c) $\mathrm{NaNO}_{3}$ d) $\mathrm{Na}_{2} \mathrm{SO}_{4}$ e) $\mathrm{NaCl}$ f) $\mathrm{NaClO}_{4}$ at poly (3MT) modified sensor.

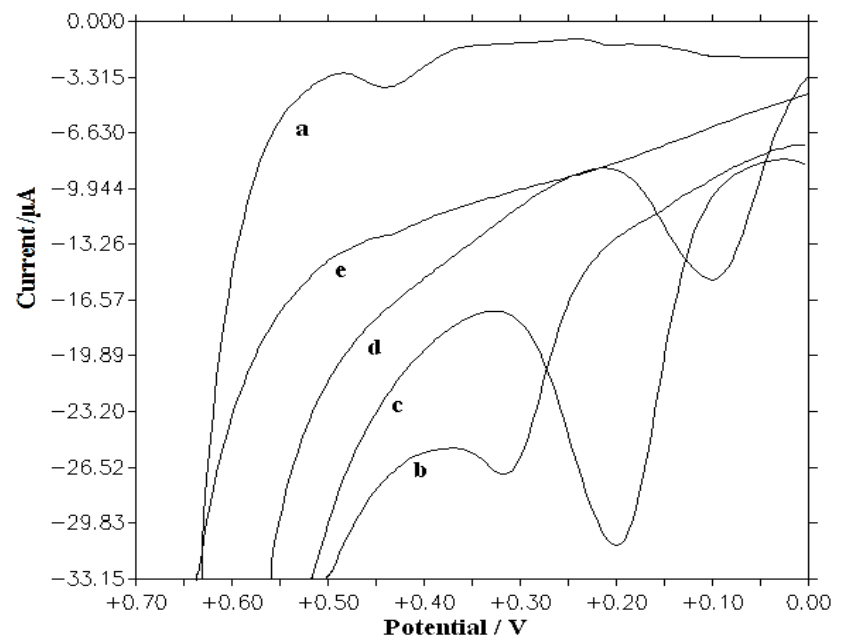

Figure 3. DPVs of $0.1 \mathrm{mM}$ DOPAC in PBS at $\mathrm{pH}$ a) $3.0 \mathrm{~b}$ ) 5.0 c) 7.0 d) 9.0 e) 11.0 at poly (3MT) modified sensor.

\subsection{Electrochemical behaviour of DOPAC at poly (3MT) modified sensor and bare Au electrode}

Cyclic voltammetry (CV) and DPV techniques were performed to observe the electrochemical behaviour of DOPAC. The determination of DOPAC was carried out both at the bare Au electrode and at the poly (3MT) modified sensor in 0.1 M PBS (pH 7.0) by using CV and DPV techniques (Figure 4). In Figure 4A, the $\mathrm{CV}$ measurements provided reduction peaks only at approximately $0.81 \mathrm{~V}$ and $0.62 \mathrm{~V}$ at the bare $\mathrm{Au}$ electrode (curve b). There was no redox reaction and the bare Au electrode process was irreversible. However, we observed sharp and well-defined reversible redox peaks as well as improved electrochemical response at the modified sensor with a peak to peak separation of $34 \mathrm{mV}$ (curve c). The modified sensor showed oxidation and reduction peaks at approximately $257 \mathrm{mV}$ and $223 \mathrm{mV}$, respectively. This was related to the fact that the redox reaction of DOPAC was faster at the modified sensor than at the bare electrode. Additionally, the redox peaks at the modified sensor showed high stability in subsequent cycles. After the bare Au electrode was modified with 3MT, the peak currents and area increased, which might be due to the fact that the poly (3MT) film had characteristic surface area and excellent electrical conductivity. Figure 4B shows the DPVs of $0.1 \mathrm{mM}$ DOPAC at the bare electrode and at the modified sensor. The oxidation peak current of DOPAC selected as the analytical signal was observed at nearly $0.20 \mathrm{~V}$ for the modified sensor and at nearly $0.33 \mathrm{~V}$ for the bare electrode. The modified sensor relatively improved the response of DOPAC in comparison to the bare electrode, and the highest peak currents and sharp peaks were obtained with the poly (3MT) modified sensor. The oxidation peak current at the modified sensor was about 17-fold higher than at the bare electrode, and more sharp peaks were observed in comparison to the bare electrode. The modified sensor dramatically enhanced DOPAC oxidation.

\subsection{Simultaneous determination of AA, DOPAC and UA at poly(3MT) modified sensor}

Simultaneous determination was carried out by DPV in the selected buffer solution. The acquired electrochemical responses of AA, DOPAC and UA were compared to see the enhancement of 3MT modification. The bare electrode could not separate the oxidation peaks of the mixture. Figure 5 displays the DPVs that were obtained to determine AA and DOPAC simultaneously at the modified sensor. In order to see the selectivity of the poly (3MT) modified electrode towards DOPAC, a mixture of DOPAC $(10,20,30,40 \mu \mathrm{M})$ and AA (at a constant high concentration) was electrochemically analysed. The oxidation peaks of $1.0 \mathrm{mM}$ AA and $10.0 \mu \mathrm{M}$ DOPAC were observed at $12 \mathrm{mV}$ and $172 \mathrm{mV}$, respectively (Figure 5A). Figure 5B shows the DPVs obtained by multi-run curves of AA and DOPAC at the poly (3MT) modified sensor, and measurements are seen to be highly repeatable. Determining of DOPAC concentration in the presence of AA is a challenging task. However, the separation between the two peaks is large enough to make it easier to determine the individual concentrations of both analytes. The modified sensor with positively charged monolayer clearly distinguished the oxidation peaks of AA and DOPAC as it can be seen in Figure 5. 

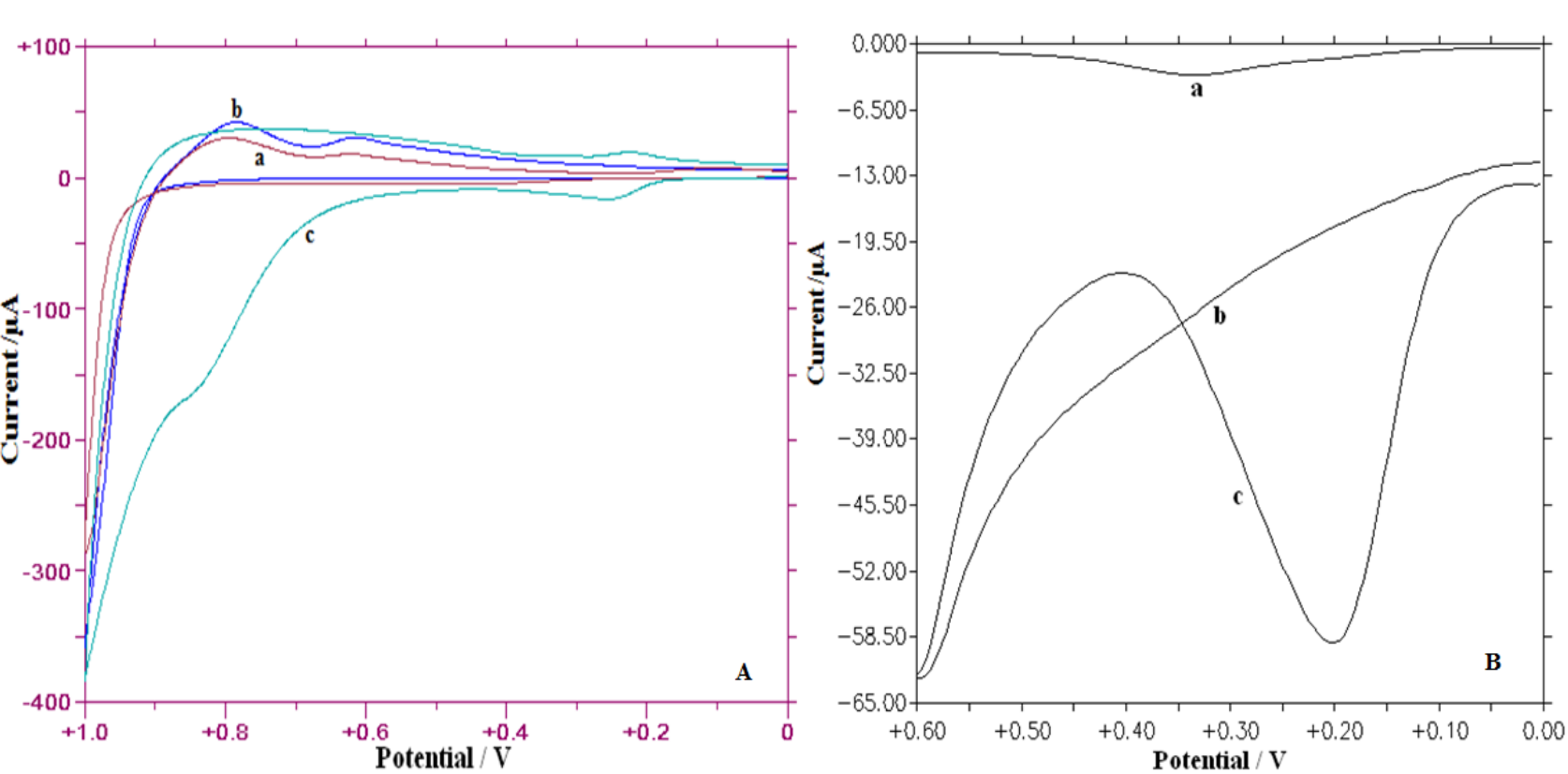

Figure 4. A) CV and B) DPV obtained for $0.1 \mathrm{mM}$ DOPAC at a) background b) bare Au electrode c) poly (3MT) modified sensor in PBS (pH 7.0).
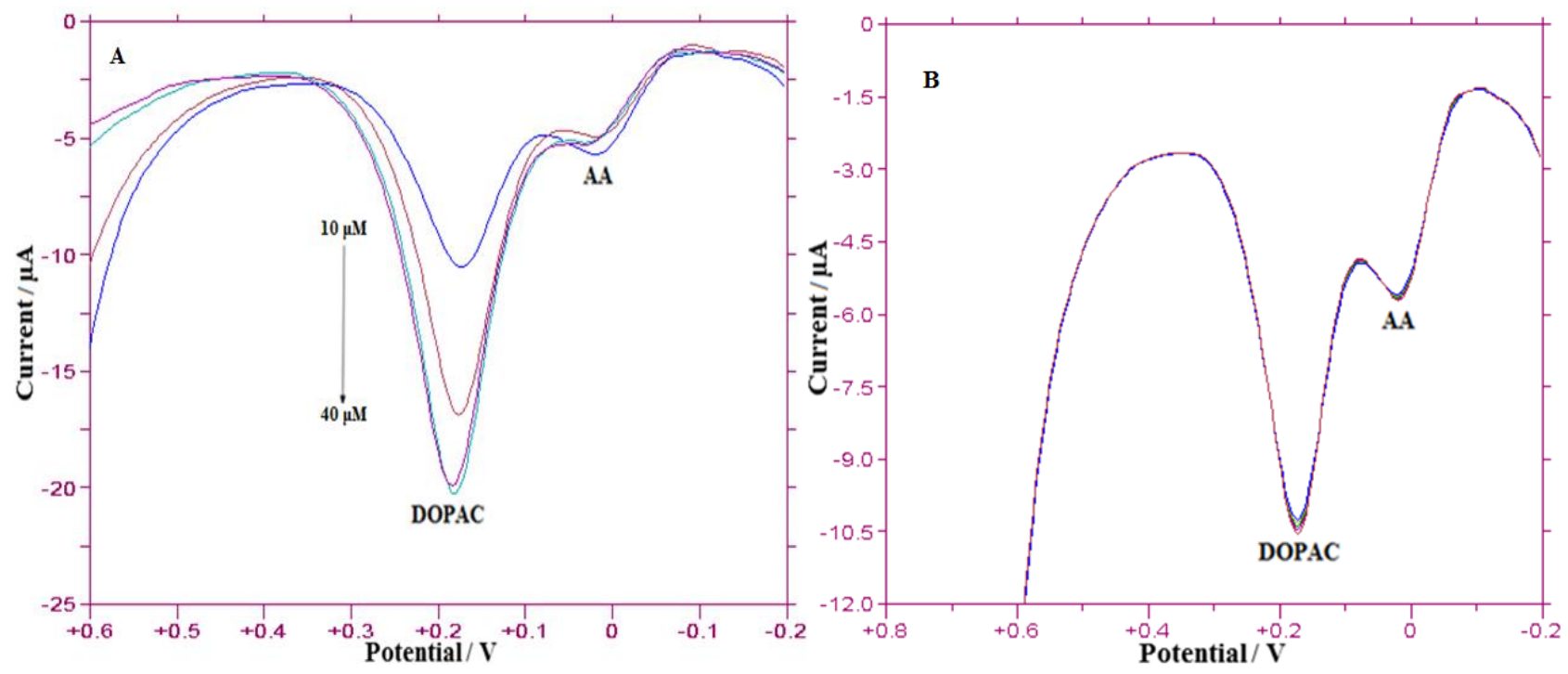

Figure 5. DPVs of DOPAC and AA at poly (3MT) modified sensor in PBS (pH 7.0). A) 1.0 mM AA and 10, 20, 30, 40 $\mu \mathrm{M}$ DOPAC B) $1.0 \mathrm{mM} A A$ and $10 \mu \mathrm{M}$ DOPAC.

An interference study was performed by DPV for UA in the presence of DOPAC and AA. For this purpose, the concentration of DOPAC varied by 1.0, 2.0, 3.0, 4.0, 5.0 $\mu \mathrm{M}$, and the concentrations of AA and UA were kept constant at $1.0 \mathrm{mM}$ and $0.5 \mathrm{mM}$, respectively (Figure 6A). In Figure 6A, two broad peaks were obtained at nearly $400 \mathrm{mV}$ and $615 \mathrm{mV}$ for the mixture of AA, DOPAC and UA at the bare Au electrode (curve a). AA and DOPAC were overlapped at $400 \mathrm{mV}$ at the bare electrode, and UA showed a broad peak with lower current at nearly $615 \mathrm{mV}$. Furthermore, oxidation peak currents with more positive potential shift were obtained at bare electrode. This indicates that the bare $\mathrm{Au}$ electrode is not suitable for simultaneous determination of AA, DOPAC and UA. On the other hand, the poly (3MT) modified electrode successfully separated the oxidation peaks of AA, DOPAC and UA, and sharper oxidation peaks appeared at $32 \mathrm{mV}, 192$ $\mathrm{mV}, 316 \mathrm{mV}$, respectively (Figure 6A). Figure 6B shows the multi-run curves of $10.0 \mu \mathrm{M}$ DOPAC, $1.0 \mathrm{mM}$ AA and $0.5 \mathrm{mM}$ UA at the modified sensor. Very clear and repeatable signals were acquired in simultaneous detection of AA, DOPAC and UA. More stable oxidation peaks could be seen in the subsequent cycles at the poly (3MT) modified sensor. 

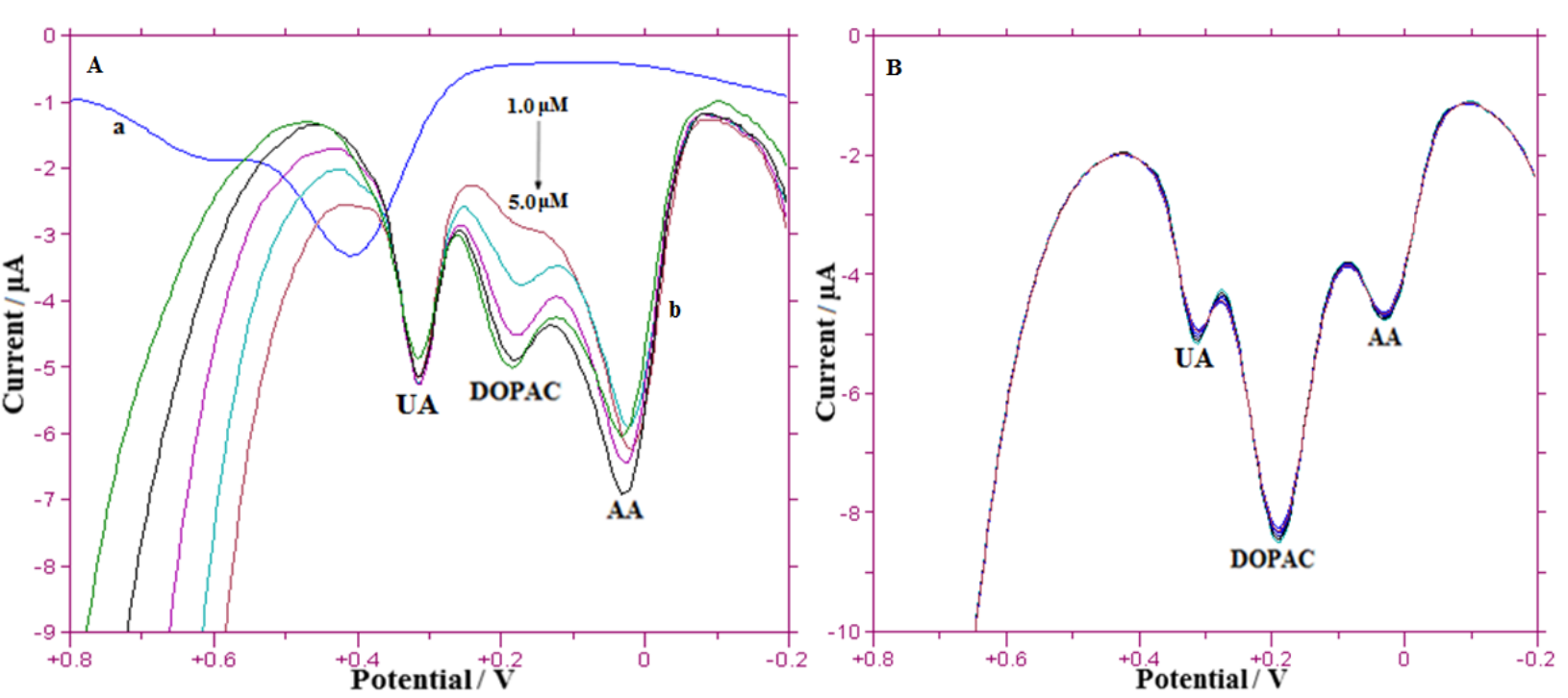

Figure 6. DPV results of A) a) $1.0 \mathrm{mM} \mathrm{AA}, 5.0 \mu \mathrm{M}$ DOPAC and $0.5 \mathrm{mM}$ UA at bare Au electrode, b) $1.0 \mathrm{mM} \mathrm{AA}$, $1.0-5.0 \mu \mathrm{M}$ DOPAC and $0.5 \mathrm{mM}$ UA at poly (3MT) modified sensor, B) 25 multirun results of $1.0 \mathrm{mM}$ AA and 10.0 $\mu \mathrm{M}$ DOPAC and $0.5 \mathrm{mM}$ UA at poly (3MT) modified sensor in PBS (pH 7.0).

It is clear that the poly (3MT) modified sensor exhibits a stronger response to DOPAC in comparison to $\mathrm{AA}$ and UA, even in the presence of high concentrations of AA and UA. AA was oxidized at a less positive potential than DOPAC, while UA was oxidized at a more positive potential than DOPAC. The oxidation peaks' potential differences between AA-DOPAC and DOPAC-UA were $160 \mathrm{mV}$ and $124 \mathrm{mV}$, respectively. This was sufficient for simultaneous detection of the analytes in a mixture. This proves that oxidations of AA, DOPAC and UA at the poly (3MT) modified sensor were independent of each other, and therefore it is possible to simultaneously or independently measure the three analytes even in the presence of any interference. The modified sensor eliminated the catalytic effects of AA and UA on DOPAC oxidation. In the presence of interferences, we obtained well-defined signals that could be separated for DOPAC very well. Based on these results, it may be stated that the electroactivity of these analytes at the poly (3MT) modified sensor was as AA > DOPAC > UA. Consequently, it was found that, even in the presence of 100-fold AA and 50-fold UA, very low concentrations of DOPAC could be readily detectable. These results show that the poly (3MT) modified sensor was quite suitable for practical applications and real samples.

\subsection{Validation of the analytical methods}

In this study, a poly (3MT) modified sensor was used for quantitative evaluation of DOPAC in a $0.1 \mathrm{M}$ PBS electrolyte at pH 7.0 using the DPV technique. A calibration graph was obtained depending on the linear correlation between the concentration and the oxidation peak currents. Quantitative experiments were performed by testing reproducibility, repeatability, stability, selectivity, sensitivity and detection limits of the modified sensor for DOPAC. All the standard solutions used in the usability tests for the modified sensor and the method were freshly prepared to ensure stability of the analytes in the solutions. Validation results and the data are listed in Table 1. Limit of detection (LOD) and limit of quantification (LOQ) values were calculated using the formula LOD $=3 \mathrm{~s} / \mathrm{m}$ and $\mathrm{LOQ}=10 \mathrm{~s} / \mathrm{m}$, where $\mathrm{s}$ is the standard deviation of the peak currents (ten measurements) and $\mathrm{m}$ is the slope of the calibration curve [31,32]. Five replicate experiments in five different solutions containing the same concentration $(10.0 \mu \mathrm{M})$ of DOPAC were performed to investigate the precision of the method within the same day (repeatability) and in different five days (reproducibility) at the modified sensor. The relative standard deviation (RSD\%) results were calculated by twenty-five measurements. The stability of the modified sensor was investigated by following the currents of $10.0 \mu \mathrm{M}$ DOPAC obtained from DPV for a month. No significant decrease was observed for 15 days. After 20 days, the current performance was $97 \%$ and it remained at $90 \%$ after a month. These results showed that the modified sensor had perfect stability, repeatability and reproducibility.

The DPV signal showed a good linear correlation with DOPAC concentration in the range from $1.0 \times$ $10^{-6}$ to $5.0 \times 10^{-5} \mathrm{M}$ at the modified sensor. The oxidation currents linearly increased while increasing the concentration of DOPAC. The linear regression equation was Ipa $(\mu \mathrm{A})=0.1315 \times C(\mu \mathrm{M})-0.2493$ with a correlation coefficient $r=0.9948$, which was obtained by six DPV measurements (Figure 7 ). The limit of 
detection and limit of quantification were $0.066 \mu \mathrm{M}$ and $0.220 \mu \mathrm{M}$, respectively. The results achieved by DPV at the modified sensor in Table 1 demonstrated that DPV exhibited wide linear range, high sensitivity, and low detection limit.

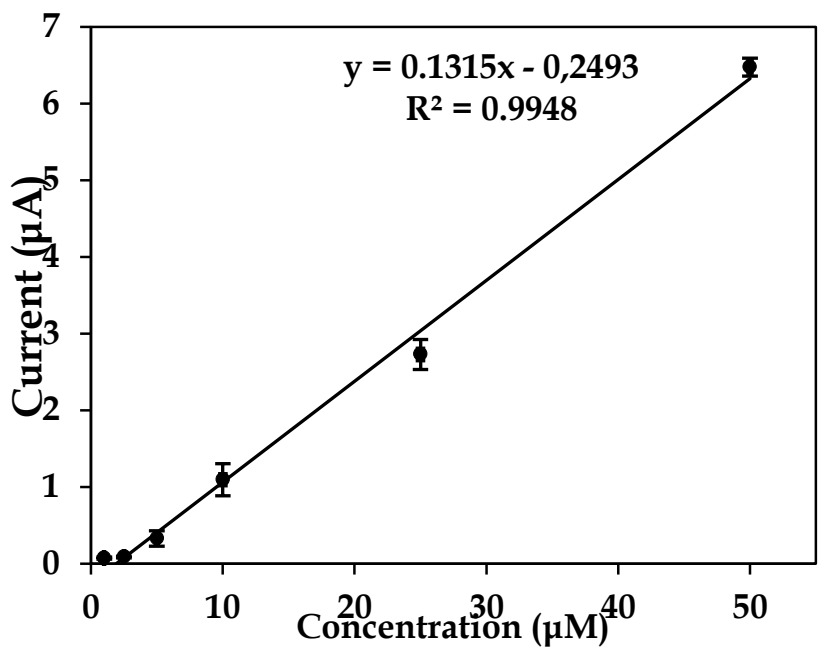

Figure 7. Calibration plot of $1.0-50.0 \mu \mathrm{M}$ DOPAC at modified sensor.
Table 1. Validation results for DOPAC at the poly(3MT) modified sensor using DPV.

\begin{tabular}{ll}
\hline Parameters & DOPAC \\
\hline Peak potential $(\mathrm{mV})$ & 220 \\
Linear concentration range $(\mu \mathrm{M})$ & $1.0-50.0$ \\
Slope $\left(\mu \mathrm{A} . \mu \mathrm{M}^{-1}\right)$ & 0.132 \\
Intercept $(\mu \mathrm{A})$ & -0.249 \\
SD of slope & 0.0284 \\
SD of intercept & 0.663 \\
Correlation coefficient $(\mathrm{r})$ & 0.995 \\
Number of measurements $(\mathrm{n})$ & 6 \\
LOD $(\mu \mathrm{M})$ & 0.066 \\
LOQ $(\mu \mathrm{M})$ & 0.220 \\
Repeatability of peak current (R.S.D. \%) & 2.34 \\
Reproducibility of peak current (R.S.D. \%) & 8.65 \\
Repeatability of peak potential (R.S.D. \%) & 0.99 \\
Reproducibility of peak potential (R.S.D. \%) & 2.26 \\
\hline
\end{tabular}

\subsection{Analytical applications}

Recovery studies were carried out in real samples (blood serum and urine) and tablets to determine the interference of additives. For this purpose, the amount that DOPAC spiked in real samples and tablets was calculated. The recovery values were calculated from the linear regression equations at an appropriate concentration range. Three replicates of each sample solution were analysed and the recovery values were calculated by taking the average of the measurements. The results are shown in Table 2 and the recoveries were in the range from $97.95 \%$ to $99.73 \%$ with RSD $<0.32 \%$. These results were satisfactory and they demonstrate that the applied sensor can be used efficiently and precisely to determine DOPAC in real samples.

Table 2. The results for DOPAC in real samples $(n=3)$.

\begin{tabular}{llllll}
\hline Medium & $\begin{array}{l}\text { DOPAC spiked, } \\
(\boldsymbol{\mu M})\end{array}$ & $\begin{array}{l}\text { Found, } \\
(\boldsymbol{\mu M})(\mathbf{n}=\mathbf{3})\end{array}$ & $\begin{array}{l}\text { Recovery, } \\
(\mathbf{\%})\end{array}$ & $\begin{array}{l}\text { RSD, } \\
\mathbf{\%}\end{array}$ & $\begin{array}{l}\text { Relative } \\
\text { Error, } \%\end{array}$ \\
\hline Human Blood Serum & 100 & 98.08 & 98.08 & 0.1182 & 1.923 \\
& 200 & 198.8 & 99.42 & 0.2886 & 0.583 \\
Human Urine & 300 & 299.2 & 99.73 & 0.01459 & 0.269 \\
& 100 & 99.69 & 99.69 & 0.2768 & 0.314 \\
Vitamin C Effervescent & 200 & 198.3 & 99.15 & 0.04161 & 0.853 \\
& 300 & 298.7 & 99.56 & 0.3248 & 0.445 \\
& 100 & 97.95 & 97.95 & 0.1448 & 2.048 \\
& 200 & 197.2 & 98.62 & 0.04362 & 1.383 \\
& 300 & 299.2 & 99.73 & 0.1023 & 0.273 \\
\hline
\end{tabular}

\section{CONCLUSION}

In conclusion, an electrochemical method was enhanced and successfully applied for sensitive and selective detection of DOPAC even in the presence of 100-fold AA and 50-fold UA. A stable modified Au electrode based on a poly (3-methylthiophene) film was prepared by the electrochemical polymerization technique in acetonitrile containing $100 \mathrm{mM}$ tetrabutylammonium tetrafluoroborate. The poly (3MT) modified sensor had an excellent response, electrocatalytic characteristics, selectivity and specificity for determination of AA, DOPAC and UA. On the other hand, the negatively charged poly (3MT) modified sensor successfully resolved the voltammetric signals of AA, DOPAC and UA and increased their oxidation currents, whereas the bare $\mathrm{Au}$ electrode could not resolve the voltammetric signals of these. Determination of DOPAC was accomplished at the modified sensor with a detection limit of $65.7 \mathrm{nM}$ using the DPV technique. The oxidation current responses were increased linearly with increasing DOPAC concentrations. The modified sensor which 
has excellent repeatability, reproducibility and stability features, can be applied in the analysis of real samples and pharmaceutical preparations without the need for time-consuming sample preparation procedures.

\section{MATERIALS AND METHODS}

\subsection{Chemicals}

3,4-Dihydroxyphenylacetic acid was purchased from Alfa Aesar. Tetrabutylammonium tetrafluoroborate, uric acid and $\mathrm{AgNO}_{3}$ were obtained from Merck. Additionally, 3-methylthiophene, acetonitrile and ascorbic acid were obtained from Sigma Aldrich. All reagents were of analytical grade. Phosphate buffer solution ( $\mathrm{pH}$ 7.0) was prepared with $\mathrm{Na}_{2} \mathrm{HPO}_{4}, \mathrm{KH}_{2} \mathrm{PO}_{4}, \mathrm{NaCl}$ and $\mathrm{KCl}$ (Merck). All experiments were carried out at room temperature. The solutions of DOPAC, ascorbic acid and uric acid were prepared fresh, and they were used within $1 \mathrm{~h}$ to avoid decomposition. All the solutions were prepared with doubly distilled deionized water.

\subsection{Instrumentation}

All the electroanalytical processes were performed by a BAS (Bioanalytical Systems, Inc.) 100W. The conventional three-electrode system was used. The working electrodes were bare (MF-2014) or poly (3methylthiophene) modified gold electrode, the auxiliary electrode was platinum-wire and reference electrode was nonaqueous $\mathrm{Ag} / \mathrm{Ag}^{+}$(CHI112). Before the electropolymerisation, the gold electrode was polished with 0.3 and $0.05 \mu \mathrm{m} \mathrm{Al} \mathrm{O}_{3}$ aqueous slurries (Johnson Matthey Catolog Comp., United States). All the pH measurements were performed by pH-meter of Hanna Instruments pH 211 Microprocessor.

\subsection{Preparation of poly (3-methylthiophene) modified Au electrode}

Electrochemical deposition was performed by $150 \mathrm{mM}$ of 3-methylthiophene and $100 \mathrm{mM}$ tetrabutylammonium tetrafluoroborate (as electrolyte) dissolved in acetonitrile. The poly (3MT) films were deposited on the gold $(\mathrm{Au}$ ) electrode surface by a controlled-potential electrolysis at a potential of $+1.7 \mathrm{~V}$ (vs. $\mathrm{Ag} / \mathrm{Ag}+$ ) for 10 secons. All the sample and the monomer solutions were deoxygenated by $\mathrm{N}_{2}$ gas and saved under the same atmosphere during the polymerization. In order to remove the unreacted monomers, the film deposited on the electrode surface was washed with acetonitrile. After the electro deposition process, the resulting terpyridine based poly (3MT) sensors were washed with doubly distilled water for subsequent electroanalytic works and air-dried for about 2 hours.

\subsection{Analytical procedures}

The validation of the studied analytical method was carried out according to accuracy, precision, robustness and stability by analyses of five sample repetitions. Recovery studies were carried out in order to clarify the accuracy and reproducibility of the method. Recovery values were calculated by using the relevant calibration equation. Calibration equations were created by plotting different concentrations of DOPAC against current values obtained from differential pulse voltammograms. The interference studies were performed in the presence of AA and UA by determining DOPAC. These interference studies were also carried out in real samples. In order to assess the accuracy of the analytical method, the recovery studies in real samples were carried out according to the methodology used in our previous study [33].

Acknowledgements: Financial support from the Research Fund Unit of İnönü University (Grant no. APYB: 2011/38) is gratefully acknowledged.

Author contributions: Concept - E.K., G.E.; Design - E.K., G.E.; Supervision - E.K., G.E.; Materials - E.K., G.E; Data Collection and/or Processing - E.K.; Analysis and/or Interpretation - E.K.; Literature Search - E.K.; Writing - E.K.; Critical Reviews - E.K., G.E.

Conflict of interest statement: The authors declared no conflict of interest.

\section{REFERENCES}

[1] Liu A, Honma I, Zhou H. Amperometric biosensor based on tyrosinase-conjugated polysacchride hybrid film: Selective determination of nanomolar neurotransmitters metabolite of 3,4-dihydroxyphenylacetic acid (DOPAC) in biological fluid. Biosens Bioelectron. 2005; 21: 809-816. [CrossRef]

[2] Kalimuthu P, John SA. Selective determination of 3,4 dihydroxyphenylacetic acid in the presence of ascorbic and uric acids using polymer film modified electrode. J Chem Sci. 2011; 123: 349-355. [CrossRef] 
[3] Wu Z, Zhao H, Xue Y, He Y, Li X, Yuan Z. Poly (pyridine-3-boronic acid)/Multiwalled Carbon Nanotubes Modified Glassy Carbon Electrodes for Simultaneous. Electroanalysis. 2010; 22: 2196-2201. [CrossRef]

[4] Moriyasu K, Ichinose T, Nakahata A, Tanaka M, Matsui T, Furuya SI. The dipeptides Ile-Tyr and Ser-Tyr exert distinct effects on catecholamine metabolism in the mouse brainstem. Inter J Pept. 2016; Article ID 6020786. [CrossRef]

[5] Raj CR, Ohsaka T. Analytical applications of functionalized self-assembled monolayers on gold electrode: voltammetric sensing of DOPAC at the physiological level. Electroanalysis. 2002; 14: 679-684. [CrossRef]

[6] Stamford JA, Palij P, Davidson C, Trout SJ. Fast cyclic voltammetry: neurotransmitter measurement in "real time" and "real space". J Bioelectrochem Bioenerg. 1995; 38(2): 289-296. [CrossRef]

[7] Valentini F, Orlanducci S, Terranova ML, Amine A, Palleschi G. Carbon nanotubes as electrode materials for the assembling of new electrochemical biosensors. Sens Actuators B. 2004; 100(1-2): 117-125. [CrossRef]

[8] Yan J, Zhou Y, Yu P, Su L, Mao L, Zhang D, Zhu D. An electrochemical sensor for 3,4-dihydroxyphenylacetic acid with carbon nanotubes as electronic transducer and synthetic cyclophane as recognition element. Chem Commun. 2008; 36: 4330-4332. [CrossRef]

[9] Salimi A, MamKhezri H, Hallaj R. Simultaneous determination of ascorbic acid, uric acid and neuro-transmitters with a carbon ceramic electrode prepared by Sol-Gel technique. Talanta. 2006; 70(4): 823-832. [CrossRef]

[10] Roy PR, Saha MS, Okajima T, Park SG, Fujishima A, Ohsaka T. Selective Detection of dopamine and its metabolite, DOPAC, in the presence of ascorbic acid using diamond electrode modified by the polymer film. Electroanalysis. 2004; 16(21): 1777-1784. [CrossRef]

[11] Raj CR, Behera SJ. Electrochemical studies of 6-mercaptonicotinic acid monolayer on Au electrode. Electroanal Chem. 2005; 581(1): 61-69. [CrossRef]

[12] Raj CR, Ohsaka T. Simultaneous electroanalysis of ascorbic acid, dihydroxyphenylacetic acid, homovanillic acid and uric acid using gold electrode modified with cationic self-assembled monolayers. Chem Lett. 2001; 30(7): 670-671. [CrossRef]

[13] Kalimuthu P, John SAJ. Size dependent electrocatalytic activity of gold nanoparticles immobilized onto three dimensional sol-gel network. J Electroanal Chem. 2008; 617(2): 164-170. [CrossRef]

[14] Maldonado S, Morin S, Stevenson KJ. Electrochemical oxidation of cathecholamines and cathechol at carbon nanotube electrodes. Analyst. 2006; 131(2): 262-267. [CrossRef]

[15] Wang J, Li M, Shi Z, Li N, Gu Z. Electrocatalytic oxidation of 3,4-dihydroxyphenylacetic acid at a glassy carbon electrode modified with single-wall carbon nanotubes. Electrochim Acta. 2001; 47(4): 651-657. [CrossRef]

[16] Liu A, Honma I, Zhou H. Electrochemical biosensor based on protein-polysaccharide hybrid for selective detection of nanomolar dopamine metabolite of 3,4-dihydroxyphenylacetic acid (DOPAC). Electrochem Commun. 2005; 7(2): 233-236. [CrossRef]

[17] Curulli A, Valentini F, Padeletti G, Viticoli M, Caschera D, Palleschi G. Smart (Nano) materials: TiO ${ }_{2}$ nanostructured films to modify electrodes for assembling of new electrochemical probes. Sens Act B: Chem. 2005; 111-112: 441-449. [CrossRef]

[18] Yeung PKF, Buckley SJ, Pedder SCJ, Dingemanse J. Determination of 3,4-dihydroxyphenylacetic acid and 5hydroxyindoleacetic acid in human plasma by a simple and rapid high-performance liquid chromatography assay. J Pharm Sci. 1996; 85(4): 451-453. [CrossRef]

[19] Adcock JL, Barnett NW, Costin JW, Francis PS, Lewis SW. Determination of selected neurotransmitter metabolites using monolithic column chromatography coupled with chemiluminescence detection. Talanta. 2005; 67(3): 585-589. [CrossRef]

[20] Drujan BD, Alvarez N, Borges JMD. A method for determination of 3,4-dihydroxyphenylacetic acid and 3,4dihydroxymandelic acid in urine. Anal Biochem. 1966; 15(1): 8-17. [CrossRef]

[21] Liu A, Wei M, Honma I, Zhou H. Biosensing properties of titanatenanotube films: selective detection of dopamine in the presence of ascorbate and uric acid. Adv Functional Mat. 2006; 16(3): 371-376. [CrossRef]

[22] Wu Z, Zhao H, Xue Y, Li X, He Y, Yuan Z. Simultaneous determination of 3,4-dihydroxyphenylacetic acid, uric acid and ascorbic acid by poly(L-Arginine)/multi-walled carbon nanotubes composite film. J Nanosci Nanotechnol. 2011; 11(2): 1013-1018. [CrossRef]

[23] DuVall SH, McCreery RL. Control of catechol and hydroquinone electron-transfer kinetics on native and modified glassy carbon electrodes. Anal Chem. 1999; 71(20): 4594-4602. [CrossRef] 
[24] Rubianes MD, Arribas AS, Bermejo E, Chicharro M, Zapardiel A, Rivas G. Carbon nanotubes paste electrodes modified with a melanic polymer: Analytical applications for the sensitive and selective quantification of dopamine. Sens Act B: Chem. 2010; 144(1): 274-279. [CrossRef]

[25] Mulla IA, Lowry JP, Serra PA, O’Neill RD. Development of a voltammetric technique for monitoring brain dopamine metabolism: compensation for interference caused by DOPAC electrogenerated during homovanillic acid detection. Analyst. 2009; 134: 893-898. [CrossRef]

[26] Huang SW, Ho KC. An all-thiophene electrochromic device fabricatedwith poly(3-methylthiophene) and poly(3,4ethylenedioxythiophene). Sol Energ Mat Sol Cells. 2006; 90: 491-505. [CrossRef]

[27] Millán WM, Smit MA. Study of electrocatalysts for oxygen reduction based on electroconducting polymer and nickel. J Appl Polym Sci. 2009; 112: 2959-2967. [CrossRef]

[28] Liu C, Lu B, Fan C, Xu J, Li Y, Jiang F. Electrochemical copolymerization of 9,10-dihydrophenanthrene and 3methylthiophene and characterization of their copolymer with tunable fluorescence properties. J Solid State Electrochem. 2010; 14: 1153-1161. [CrossRef]

[29] Huong VT, Shimanouchi T, Quan DP, Umakoshi H, Viet PH, Kuboi R. Polymethylthiophene/Nafion-modified glassy carbon electrode for selective detection of dopamine in the presence of ascorbic acid. J Appl Electrochem. 2009; 39: 2035-2042. [CrossRef]

[30] Zhang H, Zhao J, Liu H, Liu R, Wang H, Liu J. Electrochemical determination of diphenolsand their mixtures at the multiwall carbon nanotubes/poly(3-methylthiophene) modified glassy carbon electrode. Microchim Acta. 2010;169: 277-282. [CrossRef]

[31] ICH Guideline Q2A (R1), Validation of analytical procedures; Text and methodology, European Medicines Agency, London, UK, 2006. [CrossRef]

[32] Savan EK, Erdoğdu G. Determination of 3,4-dihydroxyphenylacetic acid in the presence of ascorbic acid and uric acid at poly(p-aminobenzene sulfonic acid) conducting polymer electrode. Polym Bull. 2017; 74: 4349-4360. [CrossRef]

[33] Sadikoglu M, Saglikoglu G, Yagmur S, Orta E, Yilmaz S. Voltammetric determination of acyclovir in human urine using ultra trace graphite and glassy carbon electrodes. Curr Anal Chem. 2011; 7(2): 130-135. [CrossRef] 